\title{
Acral manifestations of soft tissue tumors
}

\section{Kristen M. Paral, MD, Vesna Petronic-Rosic, MD, MSc*}

\author{
Section of Dermatology, University of Chicago Pritzker School of Medicine, Chicago, IL
}

\begin{abstract}
This group of biologically diverse entities is united by topographic localization to the hands and feet. Categorizing tumors by body site narrows the differential into a short list of possibilities that can facilitate accurate and rapid diagnosis. The goal of this review is to provide a practical approach to soft tissue tumors of acral locations for clinicians, pathologists, and researchers alike. What ensues in the following text is that tight coupling of the clinical picture and histopathologic findings should produce the correct diagnosis, or at least an abbreviated differential. The salient clinicopathologic, immunohistochemical, and molecular features are presented alongside current treatment recommendations for each entity.
\end{abstract}

(C) 2017 Elsevier Inc. All rights reserved.

\section{Introduction}

The entities presented herein are categorized on the basis of morphogenesis (where possible) and by biologic potential as benign, intermediate, and malignant neoplasms.

\section{Fibrous and related tissues: Benign lesions}

The ontogenetic classification of benign lesions reflects apparent fibroblastic or fibroblast-like morphogenesis. More specifically, these are proliferations of varying proportions of fibroblasts or dendritic stromal cells. Demystification of the topic of dermal dendritic cells is forthcoming, but for the purposes of this review, they can be divided into $\mathrm{CD}_{3} 4^{+}$and FXIIIa ${ }^{+}$groups. They are histologically similar to fibroblasts, which are characterized by a spindled to stellate cell shape with delicate, amphophilic cytoplasm, oblong nucleus with fine chromatin, and one or two dotlike nucleoli (as seen in Figure 1B). Fibroblasts lack a specific immunophenotype, but when activated, they express smooth muscle

\footnotetext{
* Corresponding author. Tel.: +1 7737026559 .

E-mail address: vrosic@medicine.bsd.uchicago.edu (V. Petronic-Rosic).
}

actin (SMA) and are deemed "myofibroblasts."1 The tumors under this heading express combinations of CD34, FXIIIa, and SMA. The synthesis of collagen by fibroblasts translates to a fibrous consistency that clinically imparts a firm texture on palpation, and, macroscopically, a gray-white or white-tan cut surface. The entities discussed next have no metastatic potential; that is, simple excision is adequate.

\section{Fibroma of tendon sheath}

Also known as tenosynovial fibroma, compared with other tumors under this heading, fibroma of the tendon sheath involves the deepest tissue plane (tendons). A wide age range is affected, but there is a predominance between the third and fifth decade. Men are more often affected. Lesions involve tendons of the fingers (49\%) - especially the thumbfollowed by the hands $(21 \%)$ and the wrist $(12 \%)$. Patients present with a slow-growing, mildly tender mass reaching a size no greater than $2 \mathrm{~cm}$. The most common clinical diagnosis is a ganglion cyst. In up to one in five cases, the tumor may recur. ${ }^{2,3}$ Microscopic examination discloses a wellcircumscribed collagenous lesion with a rather low concentration of spindle cells (Figure 1). Occasionally, the spindle cells configure in a $\mathrm{C}$ or S-shaped pattern, reminiscent of nodular 

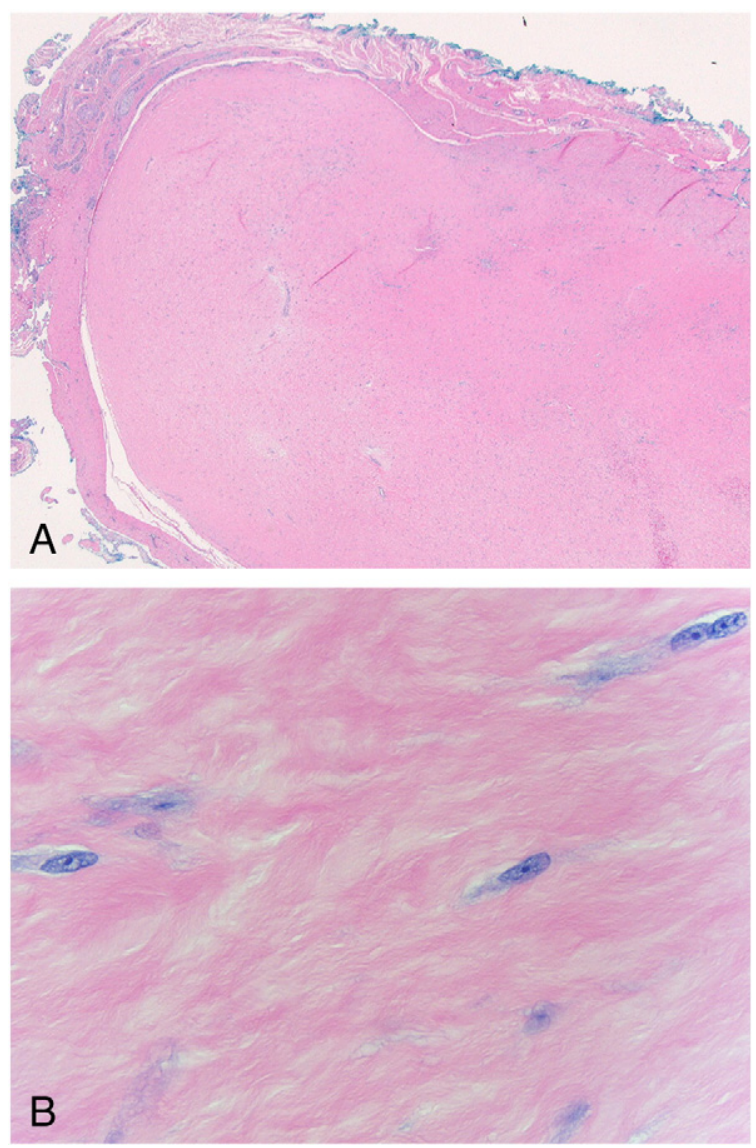

Fig. 1 Fibroma of tendon sheath. A, Low-power view reveals a circumscribed, collagenous, paucicellular nodule with peripheral clefts. B, High-power view shows few, bland fibroblastic cells in a collagenous stroma.

fasciitis. The most emphasized finding is slitlike, elongated lined clefts or vessels at the periphery, but this feature is not invariable. Immunohistochemically, SMA expression is expected. ${ }^{4}$ Limited molecular data have found the same $t(2 ; 11)$ translocation as desmoplastic fibroblastoma, ${ }^{5,6}$ supporting a neoplastic process, but some researchers still favor a reactive pathogenesis. $^{7}$

\section{Acral angiofibromas: Fibrokeratomas}

Acral angiofibromas are a clinically divergent group united by their microscopic features. The literature has permitted an unnecessarily large number of terms for the same entity, such as "acquired digital fibrokeratoma," "acquired periungual fibrokeratoma," and the fanciful "garlic clove fibroma." 8 Even the fibromas associated with tuberous sclerosis have claimed a space therein. ${ }^{9-11}$ Clinically, these lesions usually present as a single dome-shaped or hornlike lesion several millimeters in diameter (Figure 2), with a preference for the fingers. Multiple or multilobulated fibromas may occur in tuberous sclerosis and can be subungual or periungual. They may be diagnosed clinically as cutaneous horns or supernumerary digit, but the latter is usually identified at birth at the base of the fifth digit.

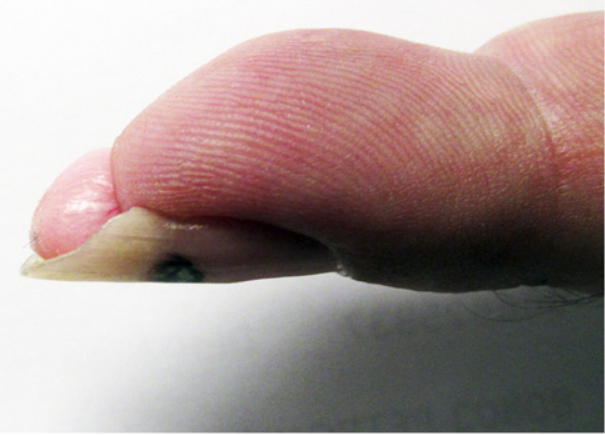

Fig. 2 Fibrokeratoma. This subungual example exhibits a pinkish color and a dome-shaped appearance.

Light microscopy reveals a hyperkeratotic and acanthotic epidermis overlying a thick core of fibrotic dermis. The dermal
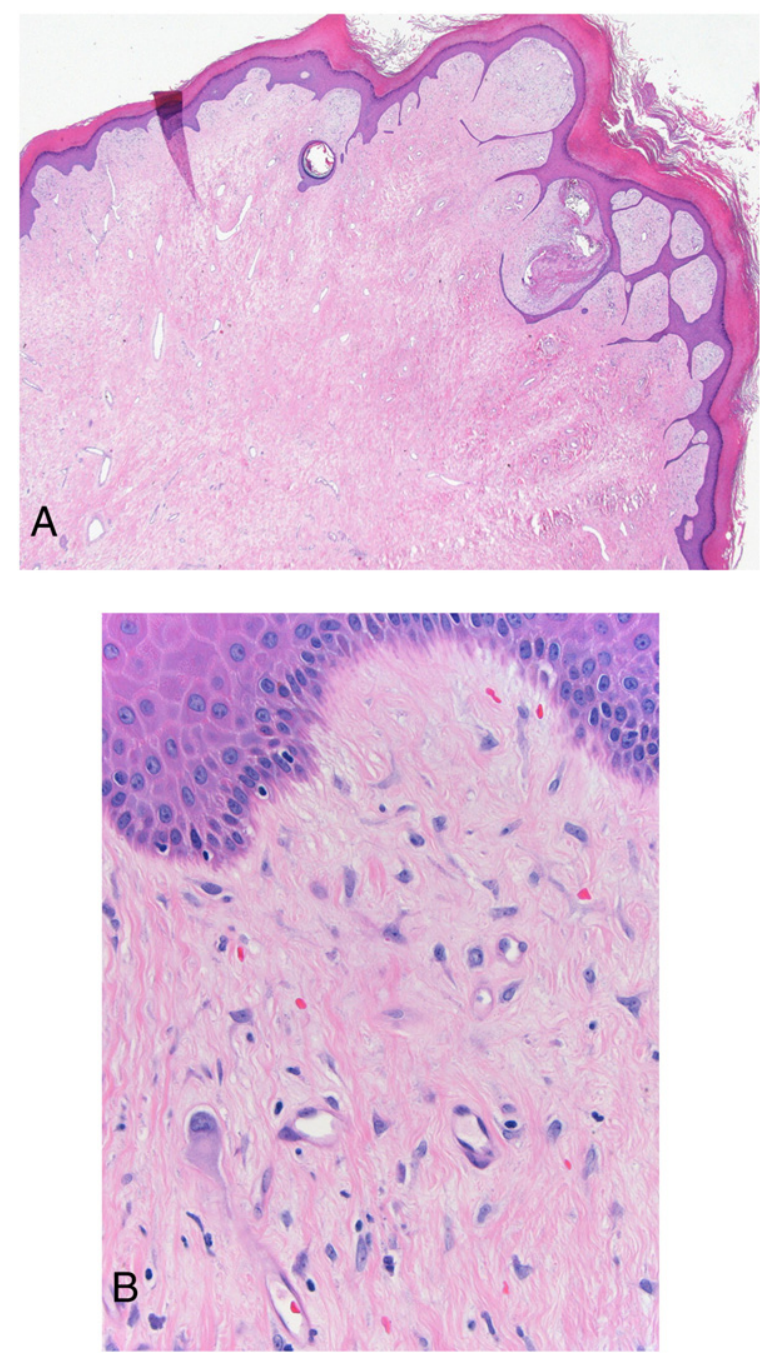

Fig. 3 Fibrokeratoma. A, A protuberant fibrous projection has a hyperkeratotic surface to which dermal collagen is vertically oriented. $\mathrm{B}$, Stellate fibroblast-like cells can be rather plump and even bizarre in form. 
collagen is oriented perpendicularly to the epidermis. Numerous thin-walled vessels are usually found. Stellate fibroblastlike cells are dispersed throughout and can be quite prominent (Figure 3). These lesions lack nerve twigs, unlike supernumerary digits. Immunohistochemistry indicates some FXIIIa expression. Molecular genetic data are lacking, but rare cases have been associated with $R b$ aberrations. ${ }^{9,10,12,13}$ Various techniques have been proposed for excising difficult lesions. ${ }^{11}$

\section{Fibro-osseous pseudotumor of digits}

Fibro-osseous pseudotumor of digits may become absorbed by the umbrella term myositis ossificans, to which it is microscopically nearly identical. ${ }^{14,15}$ Notwithstanding the foregoing, it is discussed here in keeping with the traditional literature. Fibro-osseous pseudotumor of digits is a fast-growing, often painful lesion presenting as a fusiform swelling in the proximal phalanx of the index or middle finger in a young adult. Very rarely is the toe affected. There is often a history of trauma, but most patients experience pain regardless. The clinical differential may include exostosis, and in unusual, ulcerated cases, more exotic possibilities may be considered. ${ }^{16-18}$ Cut surface is red-tan and has gritty calcifications, unlike the other fibrous tumors in this category. The microscopic appearance is of a subcutaneous, multinodular, fibroblastic proliferation arranged in short, haphazard fascicles merging with irregular spicules of woven bone (Figure 4). The bone is lined by osteoblasts. Mitotic figures can be numerous. Lesional cells express some SMA. ${ }^{14}$ The molecular genetics are unknown.

\section{Superficial acral fibromyxoma}

The entity known as "cellular digital fibroma" is presumed to be the same tumor as superficial acral fibromyxoma, an assumption also endorsed by the most recent World Health Organization classification. ${ }^{19}$ Patients present with a slow-growing, solitary lesion that may be painful. A wide age range is affected without a clear gender proclivity. More than $80 \%$ affect the digits, of which almost all arise in close proximity to the nail. The palms and soles can also be involved (Figure 5). The clinical diagnosis is often fibroma or wart. In up to one in five cases, the lesion may recur. ${ }^{20,21}$ Microscopic examination reveals a dermal or subcutaneous proliferation composed of bland spindle and stellate cells within a myxoid or collagenous stroma with prominent vessels and mast cells. Cells are arranged in random, loose storiform and fascicular growth patterns (Figure 6). On inspection, the lesion may appear neural or fibrohistiocytic, which justifies the use of immunohistochemistry. The pattern of CD34 expression in this tumor is rather distinctive. CD34 expression pattern alone narrows the differential substantially when it comes to soft tissue tumors, so its expression in an acral tumor fitting the description given here assuredly clinches the diagnosis. The molecular underpinnings have yet to be determined, but sequencing studies have failed to reveal the aberrations of GNAS1 found in intramuscular or cellular myxomas. ${ }^{20}$
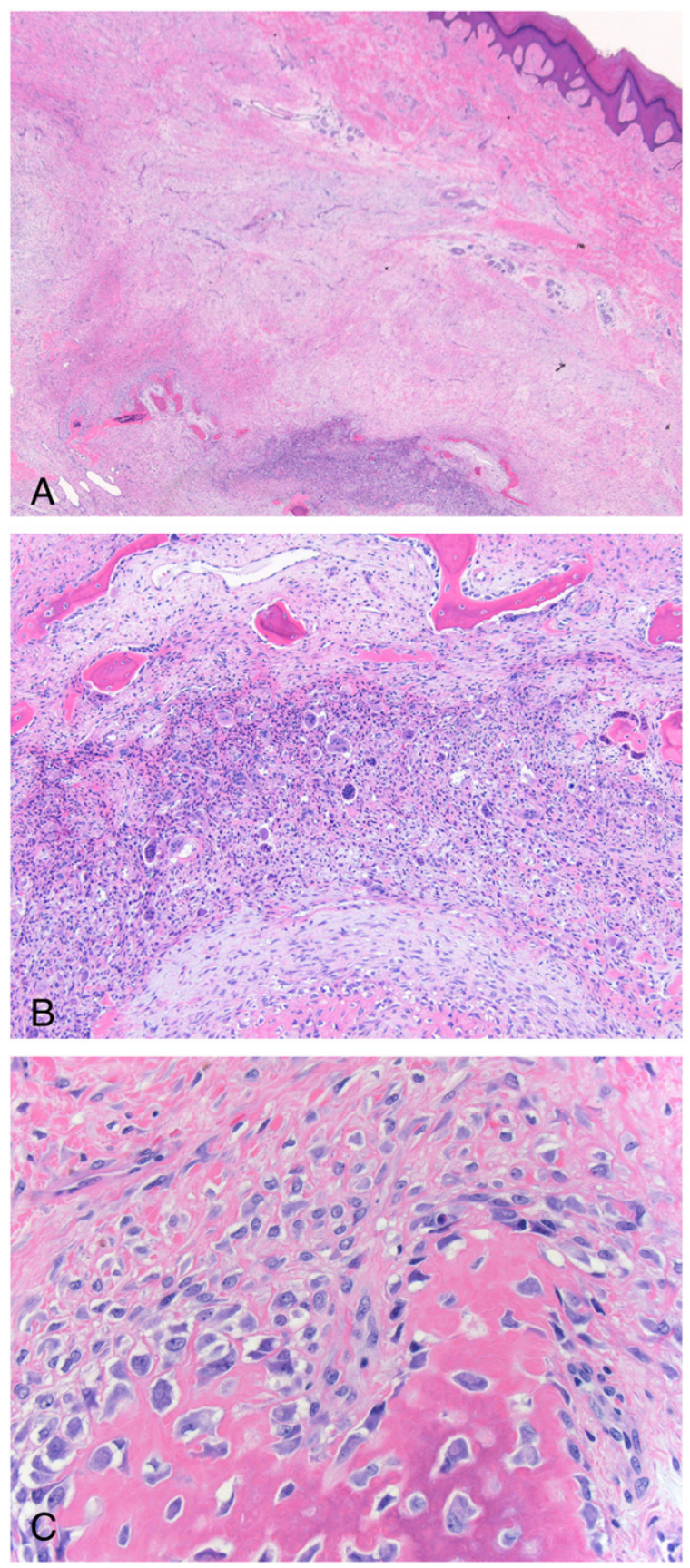

Fig. 4 Fibro-osseous pseudotumor of digits. A-C, Shown at low power is a subcutaneous proliferation with a heterogeneous appearance, consisting of a fibroblastic proliferation resembling nodular fasciitis (A), osteoclastic giant cells (B), and transition from fibroblastic cells into irregular spicules of woven bone, which harbor osteocytes and are rimmed by osteoblasts (C).

\section{Fibrous and related tissues: Intermediate lesions}

The intermediate lesions rubric encompasses the fibromatoses, defined as "nonmetastasizing fibrous tumors which tend to invade locally and recur after surgical excision."22 The key constituent cell is the myofibroblast, which was introduced earlier as an activated fibroblast expressing SMA. As the cytoplasm 

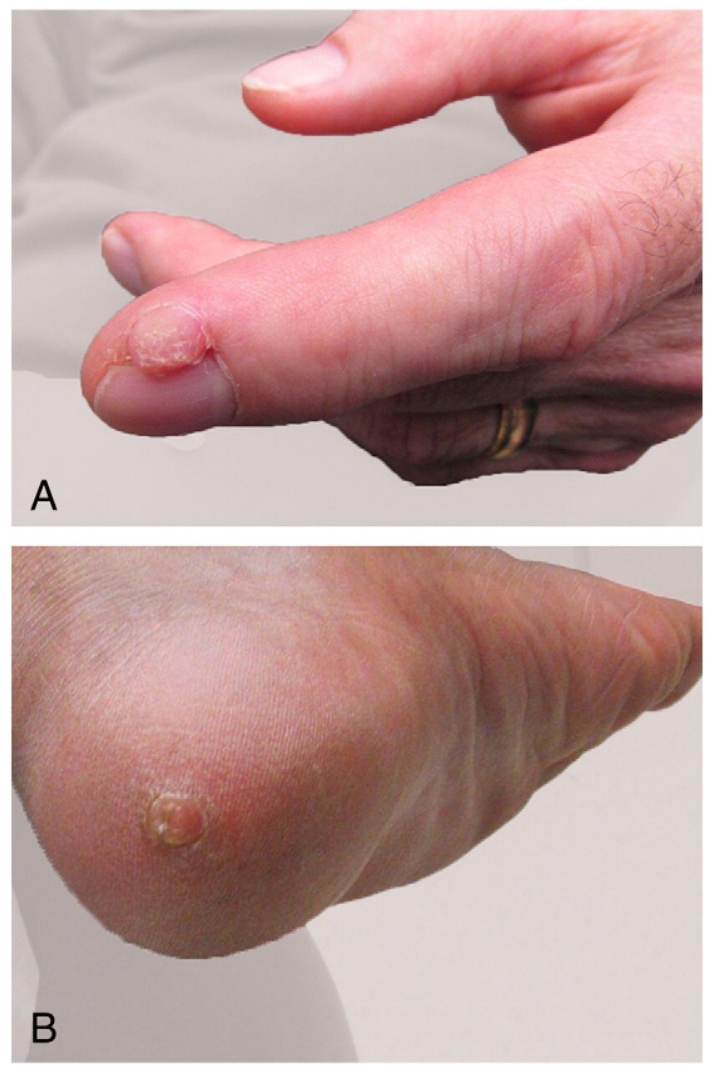

Fig. 5 Superficial acral fibromyxoma. A, These commonly present in the periungual region but can present on other acral surfaces, as shown in B. (Image B courtesy Dr. Aisha Sethi.) accumulates actin filaments, the cell borders become rigid, and cell shapes vary from bipolar to triangular (Figure 7). The nuclear features change slightly from that of the fibroblast, becoming larger and rounder. ${ }^{1}$ The gross appearance of the tumor is expectedly similar to that of the aforementioned fibrous tumors. Among the fibromatoses discussed herein, it is convenient to regard palmar-plantar fibromatosis as the prototype and to regard the others as its derivatives, with key differences highlighted here. All of these have variable numbers of mitotic figures, and they are inconsequential. Due to their intermediate tumor biology, complete excision is recommended. Discussed separately within this category is the giant cell tumor of tendon sheath.

\section{Palmar-plantar fibromatoses}

Palmar (Dupuytren) and plantar (Ledderhose) fibromatoses affect the volar acral surfaces in adults older than 30 , men more so than women. Tumors usually begin as painless subcutaneous nodules or thickenings that expand to form cordlike indurations between digits, ultimately culminating in contracture of digits (hands $>$ feet). Palmar lesions tend to affect the volar aspects of the fourth and fifth digits, whereas plantar lesions tend to involve the medial aspect of the arch. Bilateral involvement occurs in roughly half of patients. Selective fasciotomy is the treatment of choice. ${ }^{23,24}$ Excision of these lesions reveals a collection of small nodules within the subcutis and aponeurosis, with a yellow-tan appearance for younger lesions and a gray-white appearance for older ones. This agedependent difference in appearance reflects the tumor composition on light microscopy, further illustrated in Figure 7.
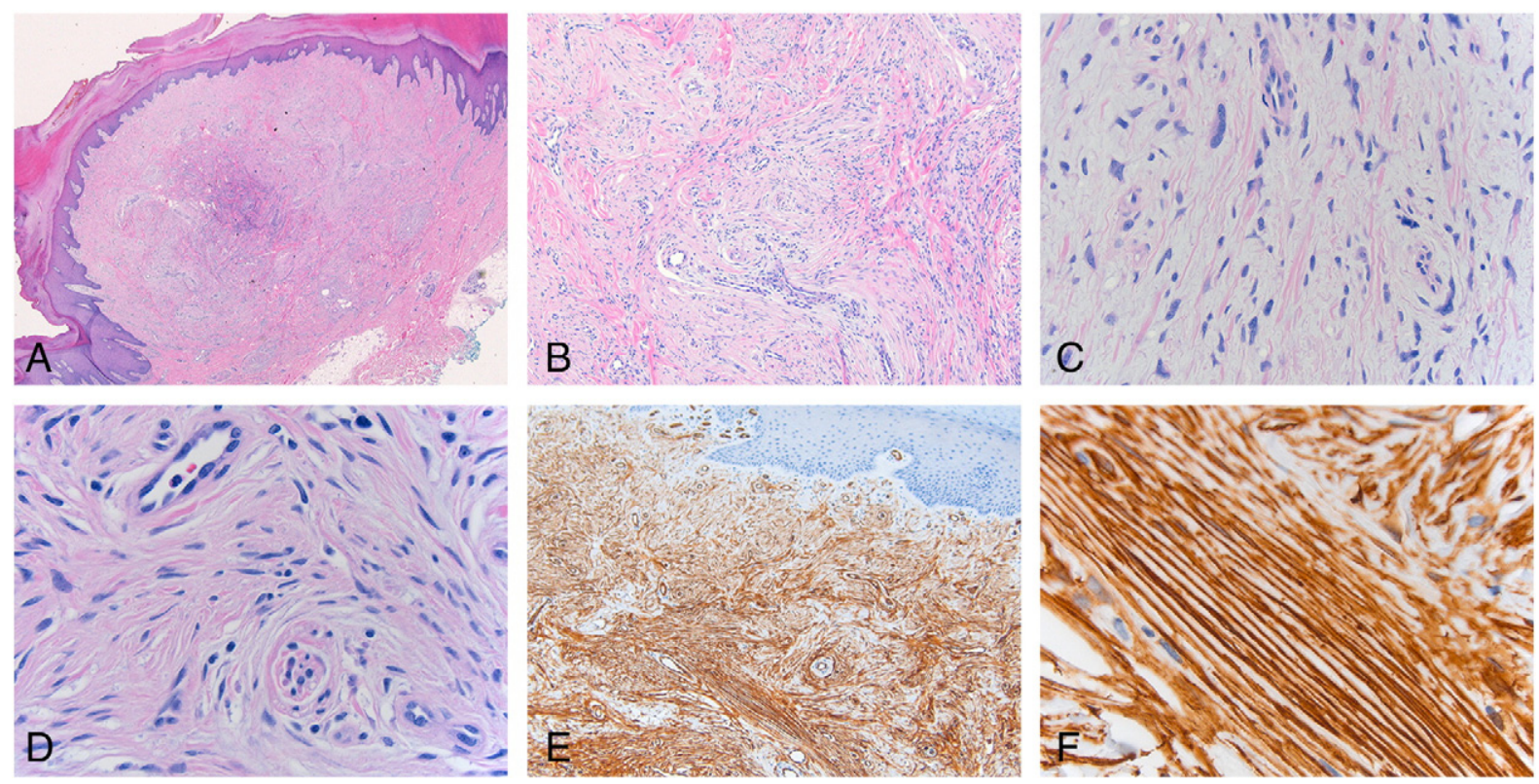

Fig. 6 Superficial acral fibromyxoma. Histopathologic examination of the heel lesion depicted in Figure 5 A-D, Microscopic examination reveals a dermal proliferation of bland spindle and stellate cells within a myxoid or collagenous stroma with prominent vessels and mast cells. Cells are arranged in random, loose storiform and fascicular growth patterns. E, This tumor has diffuse CD34 immunoreactivity, (F) shown at higher power as labeling of outrageously long, streaming dendritic processes. 

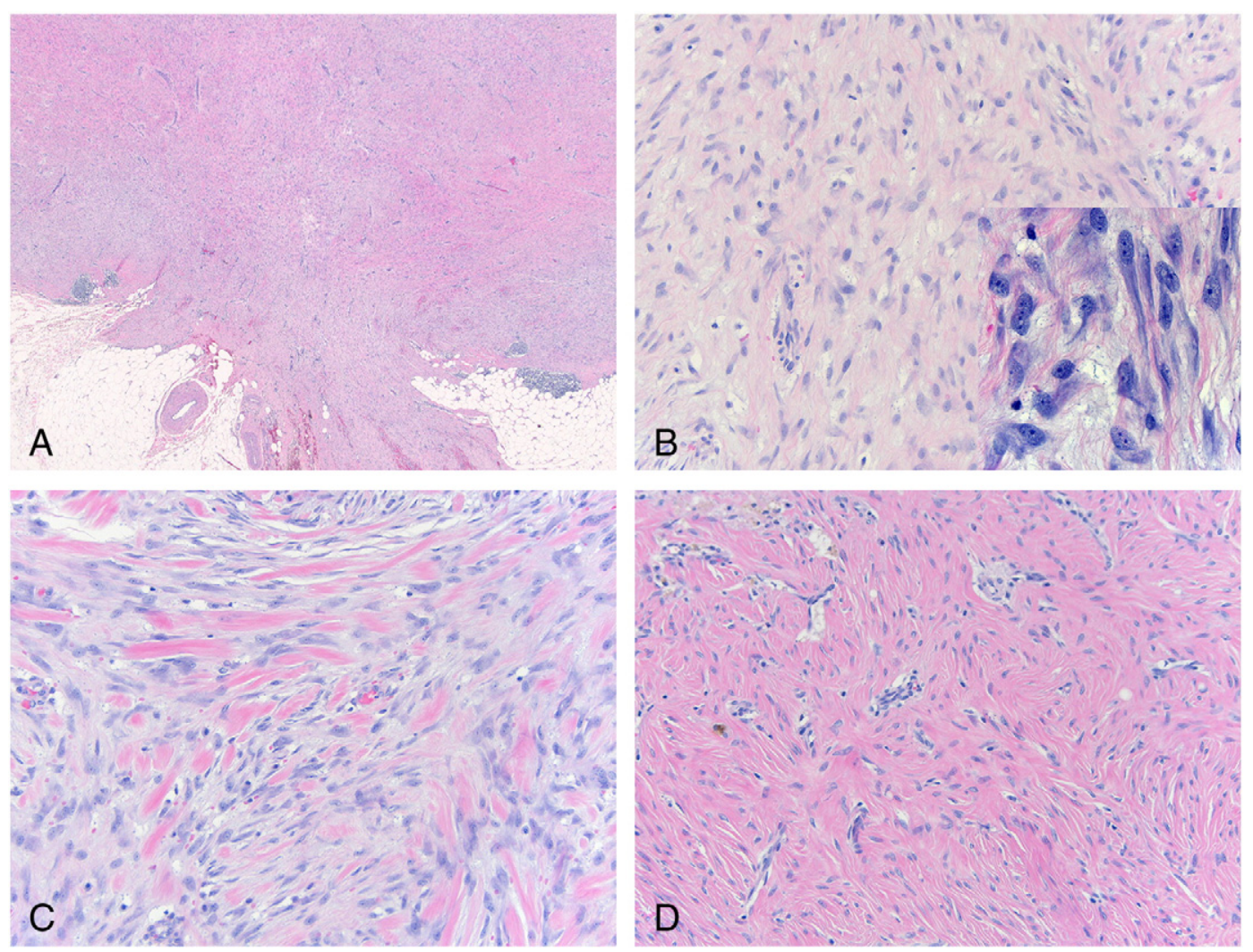

Fig. 7 Fibromatosis. A, The lesion commonly shows focal infiltration of tissues at the edge. Numerous elongated vessels are seen. B, "Younger" areas correspond to a more "active" or myofibroblastic composition, sometimes resembling nodular fasciitis; inset shows rigid bipolar and triangular cell shapes. C, Collagen is laid down as the lesion ages and can be keloidal until (D) the background is mostly collagen bearing more senescent fibroblastic cells.

Younger lesions have increased cellularity and more activated fibroblasts or myofibroblasts, compared with the more densely collagenized (often hyalinized) older lesions containing more senescent fibroblasts. The most characteristic architecture consists of sweeping fascicles of myofibroblastic cells, which often infiltrate surrounding tissues at the periphery. Slender, perpendicular vessels are common. Mitotic activity should be limited. ${ }^{25,26}$ The differential diagnosis depends on the age: The early or proliferative phase can mimic nodular fasciitis (ie, have tissue culture-like regions); later, burned out lesions are more collagenous and resemble fibromas because they are paucicellular and collagenized. Nuclear expression of $\beta$ catenin is found in roughly half of cases. ${ }^{27}$ Molecular testing for the nodular fasciitis translocation can be helpful in some cases, especially if the clinical history is ambiguous.

\section{Inclusion body fibromatosis}

The World Health Organization's preferred term is inclusion body fibromatosis (IBF), ${ }^{19}$ although several other names are enmeshed within the pathology lexicon, including "infantile digital fibroma/fibromatosis" 24,28 and the eponymous Reye tumor. The various names signal attempts to capture the most distinctive feature, which is considered to be the inclusion body. This entity could arguably be considered in the benign category given its potential to regress, but there is also substantial recurrence potential. In fact, a study of 69 patients with long-term follow-up found that $74 \%$ of patients experienced persistence or recurrence. ${ }^{28}$ Tumors affect the dorsolateral aspect of middle to distal digits II to IV in infants without a gender preference, sparing the thumb and great toe for mysterious reasons. Involvement of the dorsal surface is unique compared with the other fibromatoses discussed here. They are asymptomatic, dome-shaped or polypoid, firm, reddishpink nodules, sometimes with synchronous or metachronous lesions on different digits. The lesions often grow slowly during the first month, followed by explosive growth over the next year. ${ }^{29}$ Low-power microscopic examination yields a fibromatosis-like fibrocollagenous proliferation, with the key difference being detectable only at higher power. The moniker of this tumor is the presence of distinctive eosinophilic (hyaline) cytoplasmic inclusions (Figure 8). For some lesions, observation is an acceptable alternative to complete excision. ${ }^{28}$

\section{Calcifying (juvenile) aponeurotic fibroma}

The original description of calcifying (juvenile) aponeurotic fibroma included a small number of cases arising on the palms and soles of children ${ }^{30}$; since then, a significant number of reported cases have arisen in older ages and at 


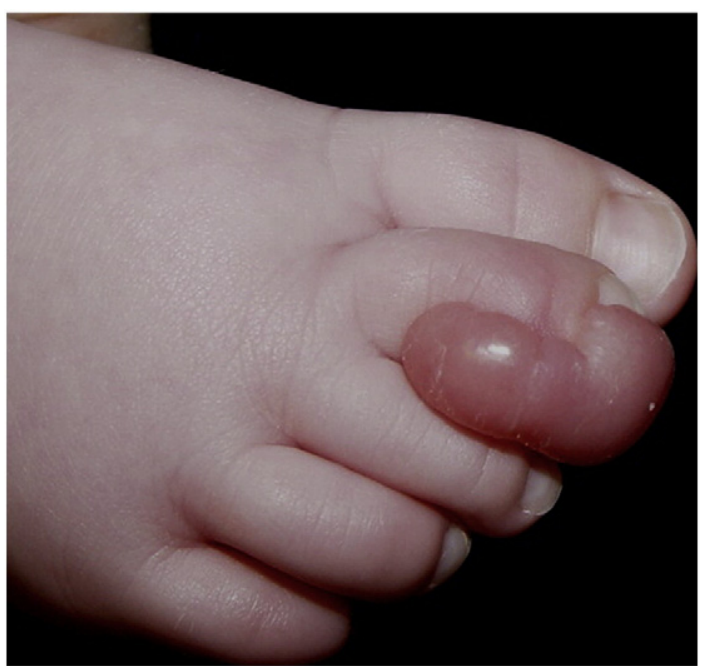

Fig. 8 Inclusion body fibromatosis. Shown here is shiny, stretched skin over a sausage-like mass on the dorsal aspect of an infant's toe. (Reproduced with permission from http://www.pcds.org.uk/, copyright (C) 1994-2016, The Primary Care Dermatology Society.)

nonacral body sites. ${ }^{31-33}$ The tumor presents as a solitary, asymptomatic, poorly circumscribed, fixed, firm mass that does not adhere to the skin or cause contractures. ${ }^{30}$ Calcifications can be seen on x-ray examination and can be detected grossly as a gritty texture. ${ }^{24}$ The histopathologic picture is that of a fibromatosis-like lesion with two major differences ${ }^{1}$ : islands of calcification that are surrounded by ${ }^{2}$ plumper, relatively epithelioid cells (Figure 9). Lesional cells may appear to grow in a continuous, sheetlike plane. There may be cartilaginous regions and a giant cell accompaniment. ${ }^{30}$ Molecular underpinnings have not yet been elucidated.

\section{Giant cell tumor of tendon sheath (localized type)}

Also called nodular tenosynovitis, giant cell tumor of tendon sheath (localized type), a so-called fibrohistiocytic tumor, exhibits fibroblast-like and histiocyte-like cells. The fibrous component permits placement under this heading of "fibrous and related tissues." The term giant cell tumor of tendon sheath (GCTTS) has evolved to encompass this tumor and the more aggressive diffuse type (pigmented villonodular synovitis) after discovery of a common pathogenesis (discussed later). The localized type of GCTTS affects the hands-especially the tendons of fingers - in the vast majority of cases. Most patients are adults, usually women, presenting with a slow-growing, usually painless swelling measuring a couple of centimeters. Macroscopic examination reveals a partial fibrous capsule surrounding a gray-white (fibrous) to yellowtan well-circumscribed nodule or mass. Histopathologic findings are characteristic, consisting of ${ }^{1}$ background osteoclastlike giant cells, xanthoma cells, and hemosiderin, and ${ }^{2}$ the main feature, a dual cell population of histiocyte-like cells and larger cells with vesicular nuclei, discussed further in

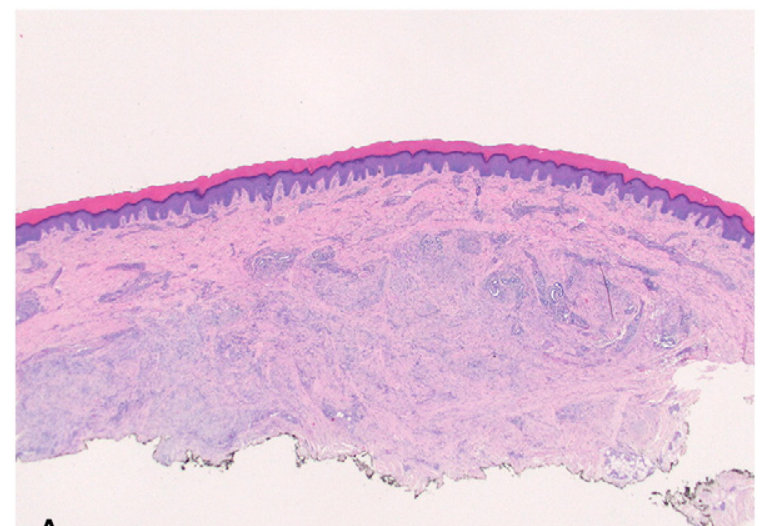

A

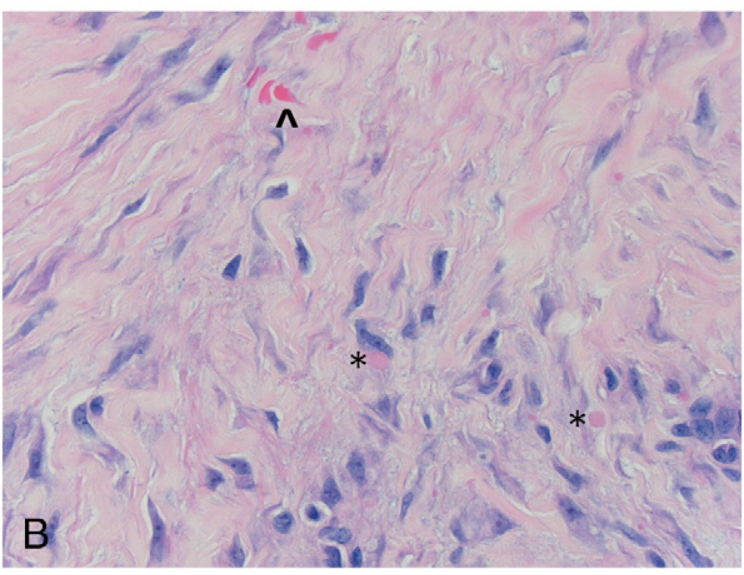

Fig. 9 Inclusion body fibromatosis. A, Shown here is dermal and subcutaneous involvement by an infiltrative fibrocollagenous proliferation mowing past adnexa. B, The moniker inclusion bodies (asterisks) are hyaline or glassy pink round structures that differ in color and shape compared with red blood cells (arrowhead).

Figure 10; these have some desmin expression. Recognition of these latter cells allows distinction from giant cell reparative granuloma, a close histologic mimic. The remaining tumor cells have variable CD68 expression. As alluded to earlier, a signature translocation underlies this neoplasm, consisting of a COL6A3-CSF1 gene fusion (translocation of chromosome 1 p13). GCTTS recurs approximately $20 \%$ of the time in a nondestructive fashion. Typically, a conservative excision with a surrounding rim of normal tissue is adequate. ${ }^{4,19,24,34,35}$

\section{Vascular and related tissues}

\section{Acral angioosteoma cutis}

The nosology of the so-called acral angio-osteoma cutis is rather contentious because it may not be a clinicopathologic entity sui generis as much as a derivative of pyogenic granuloma or a fibro-osseous lesion. This uncertainty provides a plausible explanation for its underrepresentation in major literature reviews and textbooks. Since the introduction of the term in 

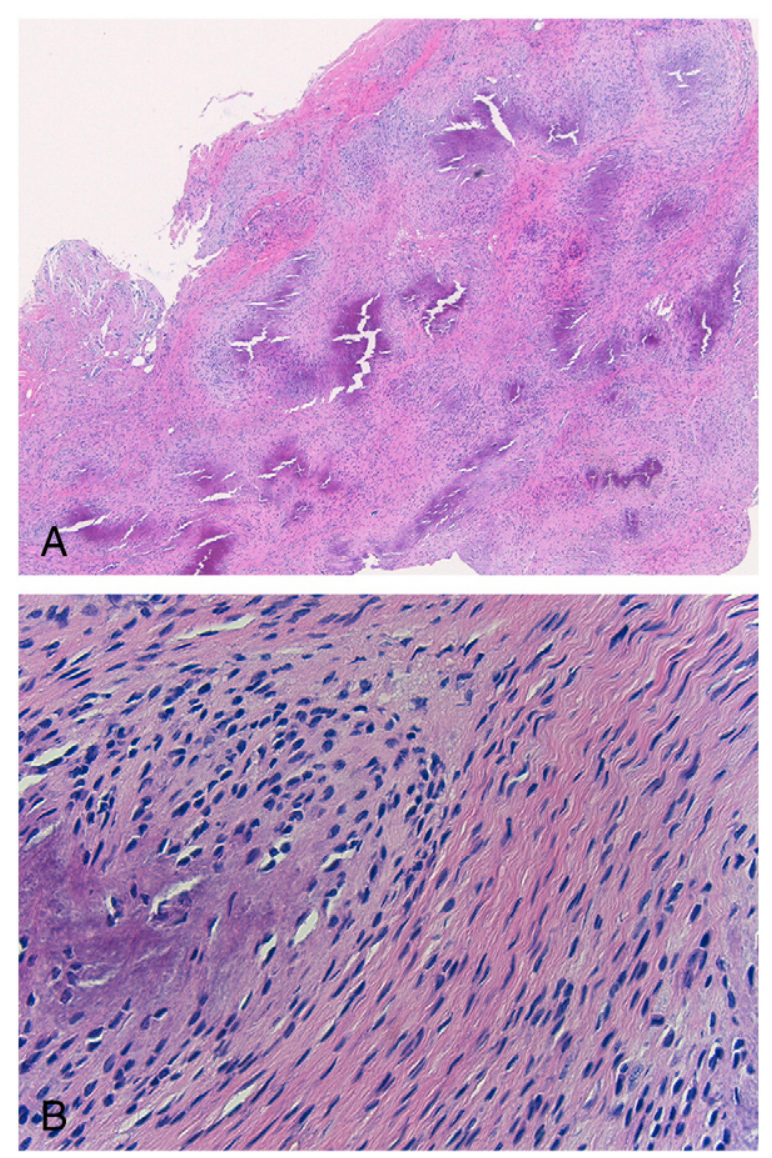

Fig. 10 Calcifying aponeurotic fibroma. A, Low-power view shows spotty calcification in a background of fibromatosis-like fibrocartilaginous proliferation. B, The lesional cells immediately surrounding the calcified islands exhibit a plumper, epithelioid cytomorphology.

2006 for a series of 11 cases, at least 3 additional cases have been reported under this name. ${ }^{36-38}$ These lesions occur on any acral site and are often periungual. They clinically and microscopically resemble pyogenic granuloma, with many having ulceration and epidermal collarettes. The main differences microscopically are diffuse rather than lobular proliferation of capillary-sized vessels, and presence of spicules of woven bone with or without osteoblasts or osteoclasts (Figure 11). The histopathologic findings superficially resemble fibro-osseous pseudotumor of digits, but they are readily distinguished by capillary content and fibrous components. Immunohistochemical and molecular data are lacking. The reported cases have had benign outcomes.

\section{Glomus tumor}

Glomus tumors are notoriously painful and do not discriminate by age or gender. Most are small $(\sim 1 \mathrm{~cm})$ violaceous nodules (Figure 12). The classic presentation of a glomus tumor consists of a triad of spontaneous pain $(80 \%)$, point tenderness
$(100 \%)$, and cold sensitivity $(63 \%) .{ }^{39}$ Several clinical tests have emerged as sensitive and specific tools for diagnosing glomus tumor, including a pin test, ${ }^{40}$ a cold-sensitivity test, ${ }^{39}$ and the so-named Hildreth test. ${ }^{41}$ These tests assess levels of pain in response to external stimuli such as direct pressure, cold temperature, or alteration of blood flow. Dermatoscopic examination may find numerous ramifying vessels within a homogeneous red-blue tumor. ${ }^{42,43}$ Although these tools can sharpen the clinical diagnosis, they cannot replace histopathologic examination.

Glomus tumors recapitulate, to varying degrees, the glomus apparatus normally present within the dermis at acral sites. The glomus apparatus consists of ${ }^{1}$ arteriovenous junctions, and ${ }^{2}$ their cloak of glomus cells which contract during thermoregulation. ${ }^{44}$ The proportions of vascular and glomus cell components seen microscopically result in variations on the name, which have no clinical bearing (eg, glomangioma, glomangiomyoma). The glomus cell component consists of nests and sheets of small, round, uniform cells with well-defined borders, amphophilic cytoplasm, and dark, punched-out nuclei (Figure 13). Thin-walled vessels are distributed throughout. ${ }^{45}$ SMA expression illustrates their myoid properties, and collagen IV envelopes individual cells (Figure 14B inset). Increased mitotic activity ( $>5 / 50 \mathrm{HPF})$, size $>2 \mathrm{~cm}$, and deep location (beneath muscular fascia) signal malignant potential. ${ }^{46}$ Symplastic change has been described in several cases of glomus tumor and must not be overinterpreted as a malignant feature. ${ }^{47,48}$ The principal differential at scanning magnification may include adnexal tumors, but further examination unveils the characteristic appearance of the glomus family of tumors. Simple excision is the mainstay of treatment. ${ }^{39}$

\section{Miscellaneous benign proliferations}

\section{Digital mucous cyst}

For the purposes of this discussion, digital mucous cyst will be considered as part of a spectrum of microscopic variation among mucous-containing lesions rather than as a unique clinicopathologic entity. One end of the spectrum overlaps with focal mucinosis, essentially embodying an exaggerated version of it (myxomatous type), whereas the other end of the spectrum exhibits a well-formed fibrous wall, sometimes connected to a joint space (ganglionic type). The typical clinical scenario is of an adult female patient presenting with a tense, smooth-surfaced, fluid-filled nodule on the dorsal aspect of the finger or toe (Figure 14). Those overlying joints are more likely to have a fibrous wall (ganglionic type). Dermatoscopic examination finds linear branched and serpentine vessels that diminish when the lesion is compressed. The microscopic findings are further detailed in Figure 15. The myxoid material is stromal mucin, which is highlighted by colloidal iron and Alcian blue ( $\mathrm{pH} 2.5)$. Excision provides definitive treatment. ${ }^{24,49-52}$ 

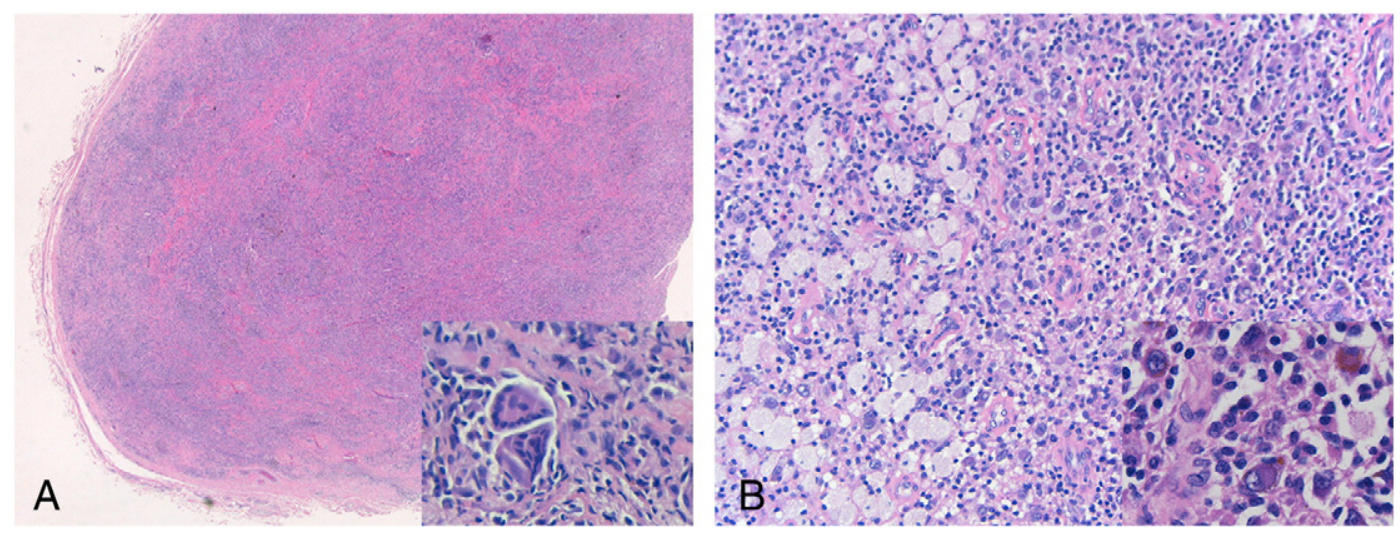

Fig. 11 Giant cell tumor of tendon sheath (localized type). A, Low-power view shows a well-circumscribed, partially encapsulated nodule with collagenous bands; the inset shows osteoclast-like giant cells. B, Xanthoma cells are seen on the left, and the right side shows a more solidappearing proliferation of mononuclear cells, some of which show an almost rhabdoid phenotype (eccentric nucleus with vesicular chromatin) and a rim of hemosiderin.

\section{Sclerosing perineurioma}

A seminal paper detailed a variant of perineurioma with a distinctive preference for the hands. Men and women of nearly all ages have been affected. Lesions are typically solitary,
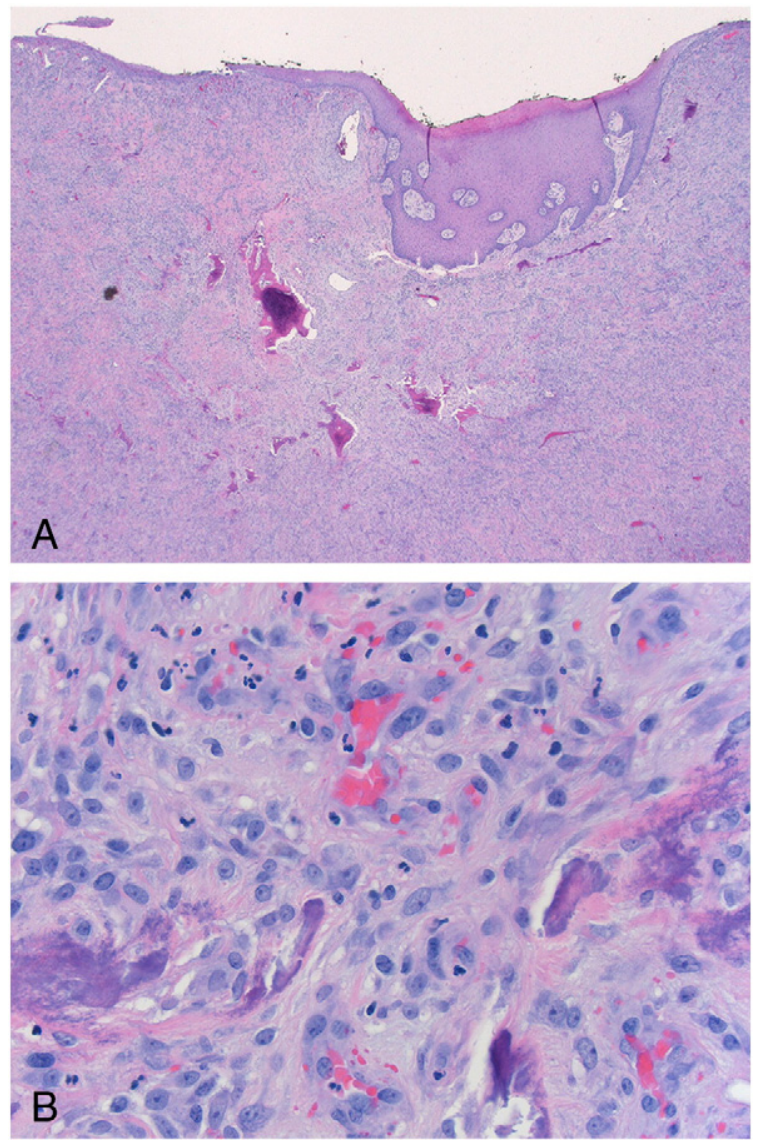

Fig. 12 Acral angio-osteoma cutis. This case involved the periungual great toe, presenting as a beefy-red polypoid mass resembling pyogenic granuloma. presenting on the fingers and palms as a painless, skincolored papule, nodule, or small tumor measuring around 3 $\mathrm{cm}$. Grossly, the tumors are fibrous, reflective of their dense, sclerotic collagen content. Lesional cells are arranged individually or in small clusters or nests, characteristically in a whorled or corded configuration. Cytomorphology ranges from spindled to epithelioid, with bland nuclear morphology. Cytoplasm can be rather inconspicuous amid the collagenous matrix (Figure 16). The histologic differential includes a sclerotic dermatofibroma or collagenous fibroma. EMA immunohistochemistry can resolve this differential, shown by diffuse expression in the lesional cells of perineurioma. These are benign neoplasms..$^{53,54}$

\section{Malignant neoplasms}

A small but varied group of entities converges under the heading of malignant neoplasms. Wide local excision (most

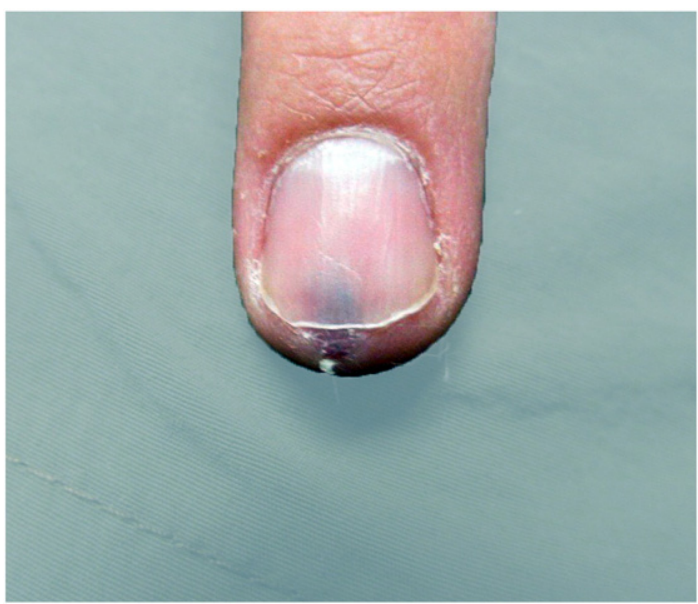

Fig. 13 Clinical appearance of glomus tumor, shown here as a violaceous subungual nodule. (Image courtesy Dr. Aisha Sethi.) 

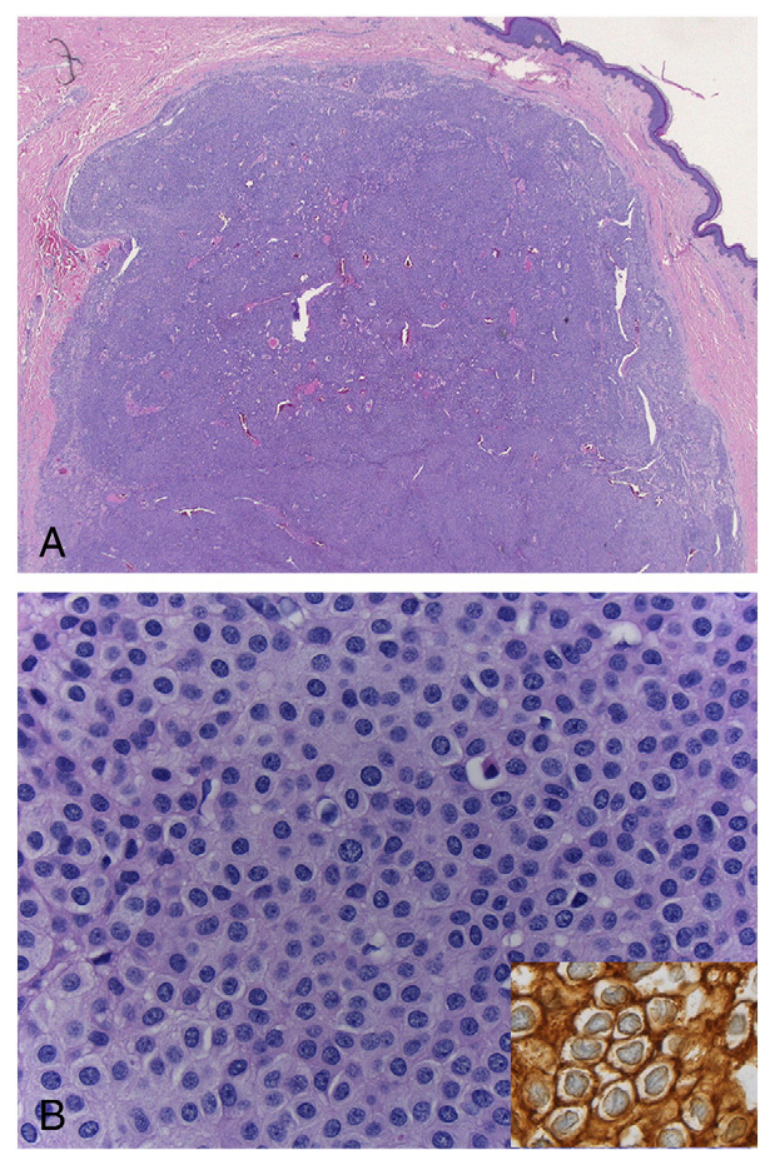

Fig. 14 Glomus tumor. A, This circumscribed dermal nodule is shown at higher power in $\mathrm{B}$, to reveal the typical cookie-cutter nuclei of glomus cells. B inset, Collagen IV immunohistochemistry highlights the round cell borders of the glomus cells.

would agree that wide local excision entails an intact fascial layer or $1 \mathrm{~cm}$ of normal surrounding tissue ${ }^{55}$ ) followed by close observation is the minimum treatment for these tumors. More aggressive care is necessary for epithelioid and clear cell sarcomas given that more than half of patients die within 10 years of these diagnoses, usually after a relentlessly progressive series of recurrences. ${ }^{56-58}$ Interestingly, both tumors have

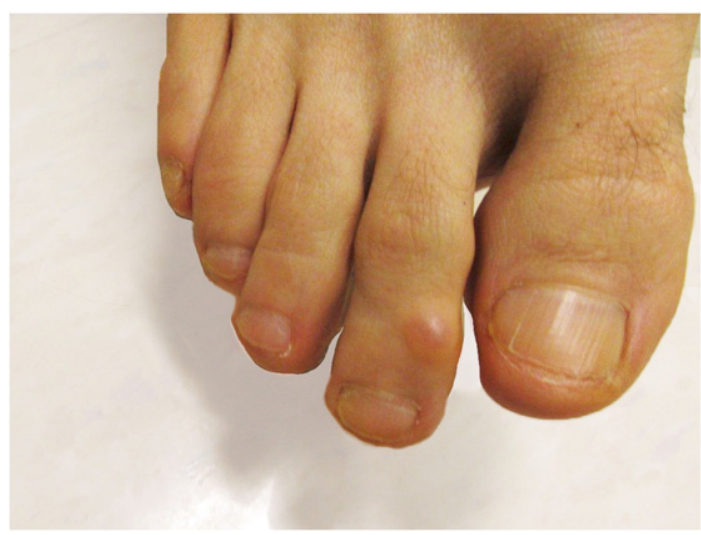

Fig. 15 Digital mucous cyst. Shown here is a tense, smoothsurfaced, fluid-filled nodule on the dorsal aspect of the toe. a marked tendency for regional lymph node metastasis (up to nearly half of cases), an unusual feature for sarcomas, which usually disseminate hematogenously to the lungs. As a result, examination of regional lymph nodes radiographically (by sentinel lymph node biopsy or by lymphadenectomy) has been recommended. Neither epithelioid nor clear cell sarcoma is chemosensitive, and the benefits of radiotherapy appear modest at best; regardless, radiotherapy is often administered as part of the standard approach to soft tissue sarcoma. Extended surveillance is indicated, because recurrences can appear after decades of quiescence. ${ }^{55,57-60}$

\section{Acral myxoinflammatory fibroblastic sarcoma}

There is a trend toward dropping the descriptor acral from the name of myxoinflammatory fibroblastic sarcoma because nonacral cases continue to emerge. ${ }^{19,61}$ "Inflammatory myxohyaline tumor" was a previous designation for this entity, ${ }^{62}$ but the current name better captures the biologic potential and apparent morphogenesis. Myxoinflammatory fibroblastic sarcoma (MIFS) is a low-grade sarcoma with a fibroblastic phenotype that most often develops on the distal extremities of adults. The digits and web spaces of acral sites, especially on the hands, are the most common locations. Lesions present insidiously as ill-defined, usually painless, slow-growing masses infiltrating and possibly traversing soft tissue planes. Only rarely does the tumor extend superficially enough to ulcerate the epidermis or deeply enough to intersect with bone. Location in the hands lends consideration to a clinical diagnosis of GCTTS. Metastatic potential is low (2\%), but recurrences are quite common, reported in up to $67 \%$ of patients. Radiotherapy has supplemented wide local excision in some cases, but data are limited on its utility. ${ }^{61}$

Gross examination discloses a multinodular lesion measuring several centimeters and having a variably myxoid to fibrous cut surface. Microscopic findings parallel the gross findings, indicating a multinodular lesion with alternating zones of fibrous and myxoid regions (Figure $17 \mathrm{~A}$ and $\mathrm{B}$ ). Constituent tumor cells range from spindled to epithelioid. A mixed inflammatory accompaniment is classic and can be exuberant, leading to an erroneous impression of an inflammatory lesion. Mitotic rate is usually low, commensurate with the low-grade biologic behavior. The most distinctive finding is the bizarre cytomorphology of ganglion-like cells and virocyte-like cells (Figure 17C). Additionally, enlarged, vacuolated "pseudolipoblasts" are also commonly found in the myxoid areas, reminiscent of myxofibrosarcoma. Immunohistochemical studies find variable expression of CD68, CD34, and SMA. Molecular studies can be sought for ambiguous cases, because translocation $\mathrm{t}(1 ; 10)(\mathrm{p} 22 ; \mathrm{q} 24)$ has emerged as a genetic signature. This translocation links MIFS to hemosiderotic fibrohistiocytic lipomatous tumor (FHLT), which bears the same translocation. FHLT is a benign tumor occurring on the feet of adult women. Both MIFS and FHLT can display hemosiderin deposition, inflammatory cells, and plump fibrohistiocytoid cells, but FHLT has a fatty component 


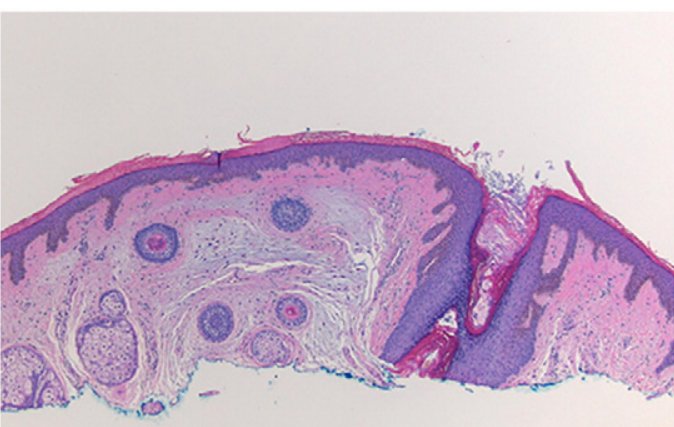

A
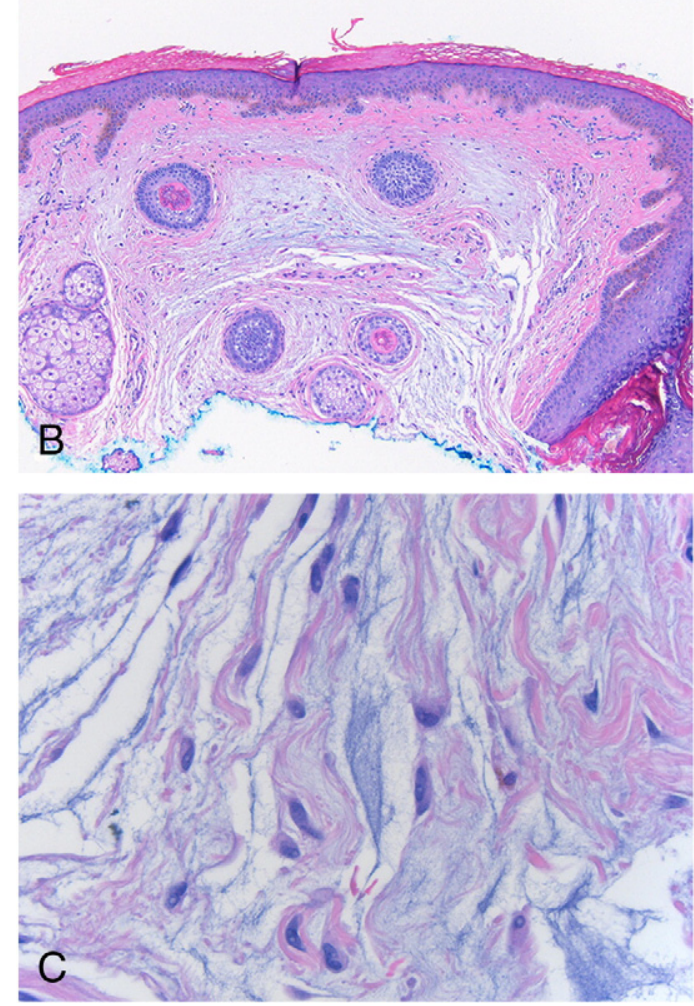
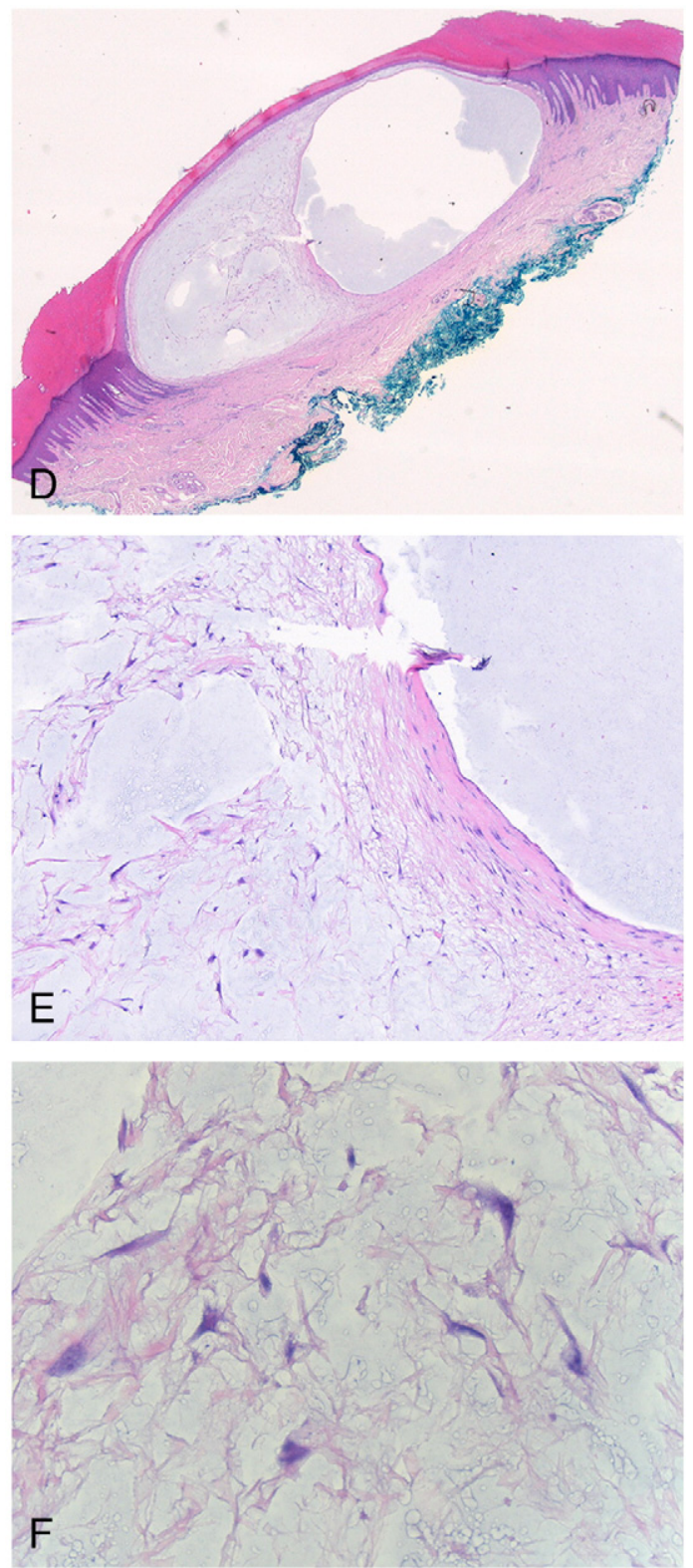

Fig. 16 A-C, Focal mucinosis, for comparison to (D-F) digital mucous cyst. Digital mucous cyst reflects an exaggerated, more circumscribed version of focal mucinosis. E, Shows the beginnings of a fibrous wall dividing the two pools of mucin in this lesion. High-power examination of focal mucinosis and myxoid cyst shows the same bland, stellate fibroblastic cells suspended in a blue-gray, stringy to bubbly matrix.

and a lack of virocyte-like cells, and strongly expresses CD34. Cases of overlapping MIFS/FHLT have been described. ${ }^{61,63}$ The underlying pathobiology of MIFS and FHLT has yet to be elucidated.

\section{Epithelioid sarcoma}

The original description of epithelioid sarcoma in the literature depicted a sarcoma of young adult men manifesting a distinct predilection for the distal extremities, particularly the hands and forearms. ${ }^{58,64,65}$ This description reflects what is now regarded as the classic or distal subtype of epithelioid sarcoma. The proximal subtype, described as a unique clinicopathologic variant, ${ }^{66}$ is not further discussed herein. The tumor presents in either a superficial or deep location. Superficial lesions are described as a "hard woody knot" and usually do not limit mobility but can ulcerate later in the course. They may be mistaken for abscesses, infected warts, or granuloma annulare. Deeper lesions are often larger, presenting as an area of firmness or localized pain. Due to the young patient age at presentation, a benign diagnosis is often presumed initially, resulting in substantial diagnostic delays of several month. ${ }^{60}$

Epithelioid sarcoma is adeptly named in two ways: 1) it mimics carcinoma in its pattern of metastatic spread to lymph nodes, as alluded to above, and 2) it mimics carcinoma 

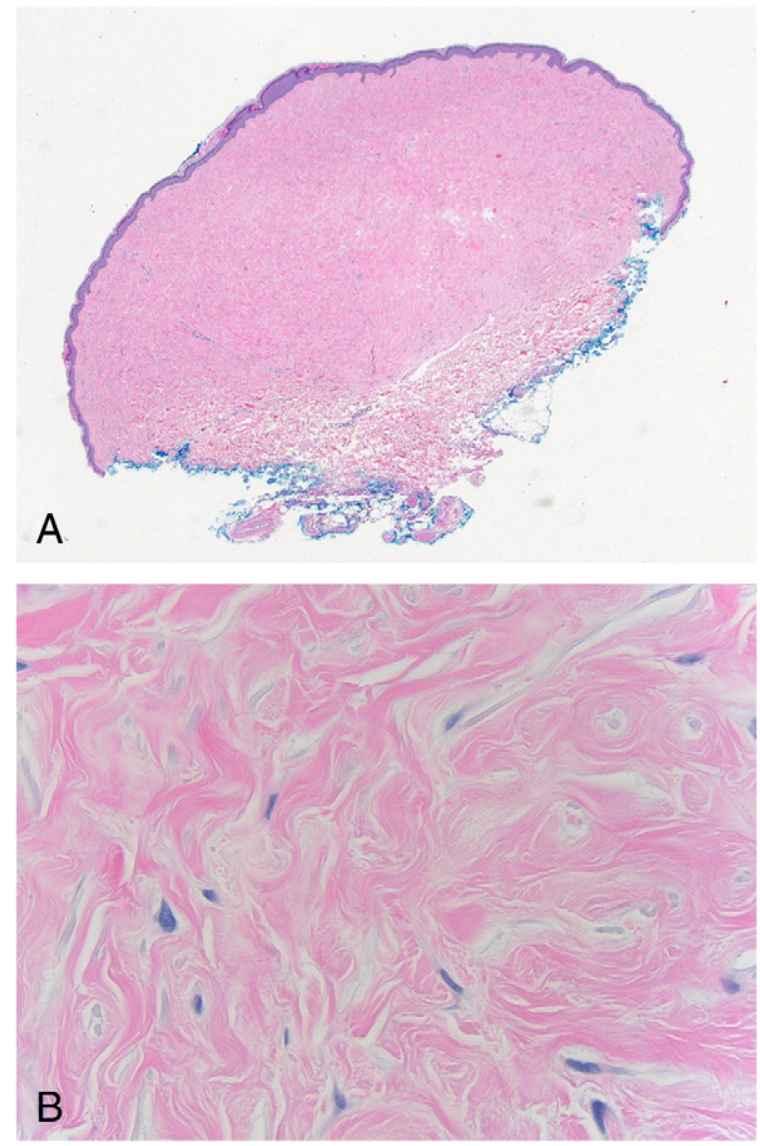

Fig. 17 Sclerosing perineurioma. The collagenous background overtakes the sparse spindle cell component. The delicate cytoplasmic processes are largely inconspicuous.

microscopically and immunohistochemically. Microscopic assessment finds variably cohesive, polygonal cells with voluminous cytoplasm, sometimes growing in waves around a zone of necrosis (Figure 18). The epithelioid phenotype is further identified immunohistochemically as clear expression of cytokeratins or EMA, usually diffusely. More than half of cases also have CD34 expression. The key marker in clinching the diagnosis is INI1, which has diffuse loss of expression throughout the tumor (Figure 19C), whereas normal cells retain expression. ${ }^{67-69}$ This loss of INI1 expression by immunohistochemistry reflects aberrations of the SMARCB1/INI1 gene on chromosome 22, a characteristic feature of the emerging and ever-evolving family of SMARCB1/INI1-deficient neoplasms. ${ }^{70}$

\section{Clear cell sarcoma}

The designation "melanoma of soft parts" has become a relic of the past, because it is now known that clear cell sarcoma is a translocation-bearing sarcoma. Clear cell sarcoma (CCS) has in common with epithelioid sarcoma a preference for the extremities of young adults, but it lacks a clear gender predominance and involves the lower rather than upper extremities.
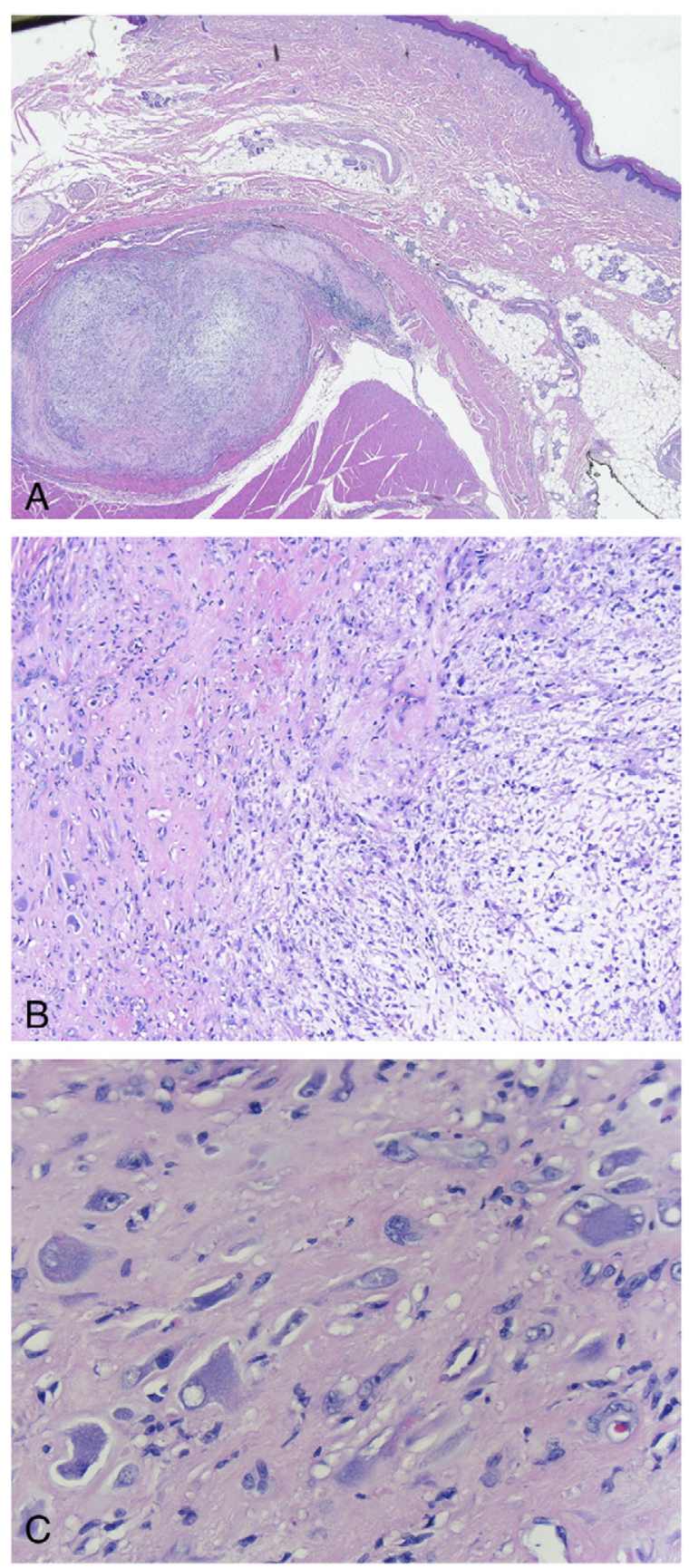

Fig. 18 Acral myxoinflammatory fibroblastic sarcoma. A, A tumor island is seen in the deep fascia and skeletal muscle. B, Fibrohyaline (left) and myxoid (right) zones comprise this lesion. C, High-power view reveals the moniker virocyte-like or ganglion-like cells, with voluminous amphophilic cytoplasm and vesicular nuclei.

The foot is most commonly involved by a nonfluctuant, slightly mobile swelling or mass usually involving tendons or aponeuroses. Some patients complain of tenderness. The mass grows slowly and is sometimes present for years before presentation. ${ }^{57,71}$ Its slow growth combined with overall circumscription and modest size (usually $<4 \mathrm{~cm}$ ) ${ }^{57,72}$ could easily engender a deceptively benign clinical impression. 

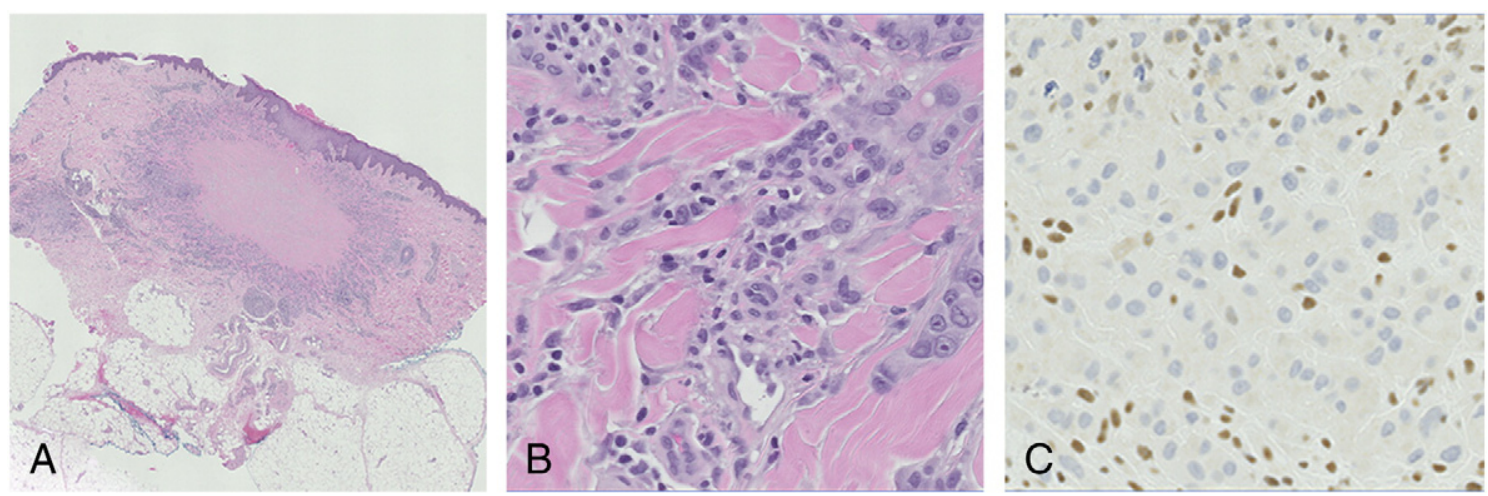

Fig. 19 Epithelioid sarcoma. A, Low-power view mimics a palisading granulomatous process. B, Closer view shows epithelioid to spindled cells with malignant cytomorphology. C, INI1 protein expression is lost by the tumor cells and retained by nonlesional cells.

Microscopic viewing reveals nests and sheets of epithelioid to fusiform cells with variably clear cytoplasm (Figure 20). Often, the cytoplasm is eosinophilic to amphophilic rather than clear (Figure 19). Delicate fibrous septa often separate the tumor nests. Nuclei are vesicular, and nucleoli are prominent. Melanin may be present. Multinucleated cells may be present, which should be lacking in melanoma. ${ }^{71}$ As is often found
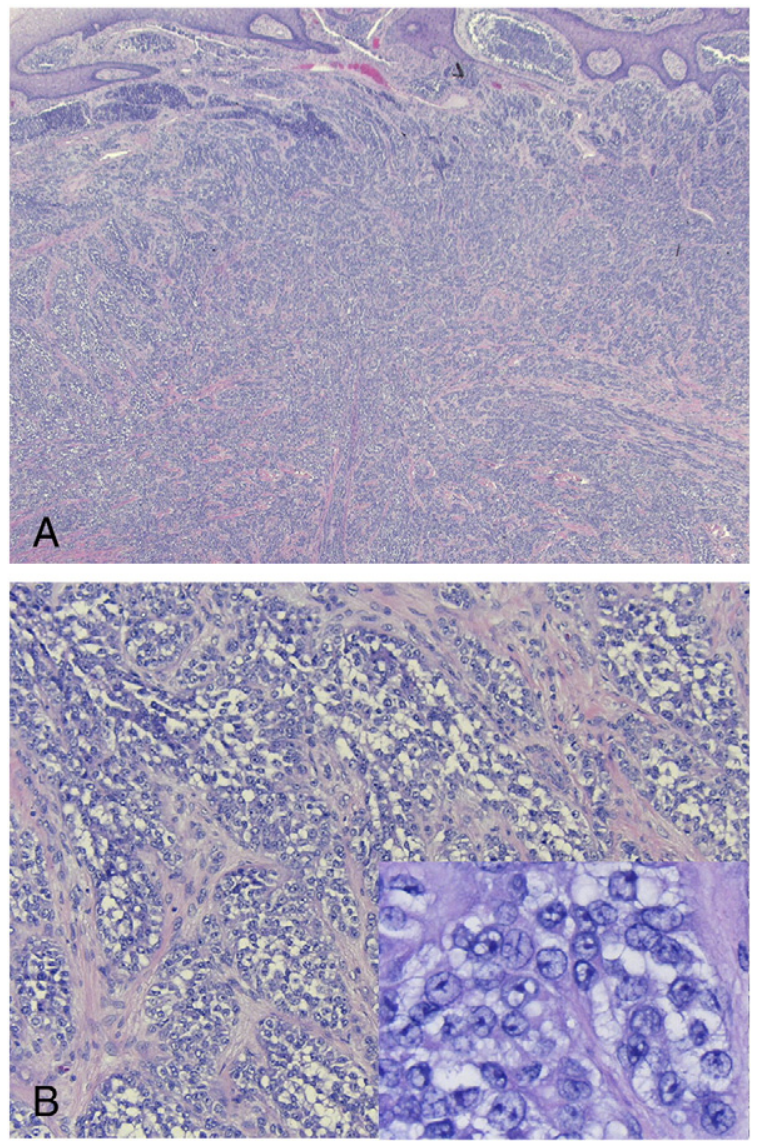

Fig. 20 Clear cell sarcoma. A, The dermis is effaced by expansive tumor growth. B, Tumor nests contain a rather monotonous cell population, consisting of cells with retracted amphophilic cytoplasm and vesicular nuclei (inset). with translocation-bearing sarcomas, there is a degree of monotony and uniformity of the neoplastic cells, in contrast to melanoma, which usually has greater pleomorphism. CCS expresses the full panel of melanocytic markers, including SOX $10 .^{72,73}$ The translocation involving the EWSR1 gene that characterizes more than $90 \%$ of $\operatorname{CCS}^{57,72}$ has never been found in a single case of melanoma. Melanoma aberrations, such as $B R A F$ or NRAS mutations, have been found in rare cases of CCS bearing the translocation. ${ }^{57}$ Given the phenotypic overlap between CCS and melanoma, it has been suggested that all extracutaneous melanotic tumors be tested for EWS gene rearrangement. ${ }^{74}$

\section{References}

1. Kalluri R, Zeisberg M. Fibroblasts in cancer. Nat Rev Cancer. 2006;392-401.

2. Chung EB, Enzinger FM. Fibroma of tendon sheath. Cancer. 1979;44: 1945-1954.

3. Pulitzer DR, Martin PC, Reed RJ. Fibroma of tendon sheath. A clinicopathologic study of 32 cases. Am J Surg Pathol. 1989;13:472-479.

4. Maluf HM, DeYoung BR, Swanson PE, et al. Fibroma and giant cell tumor of tendon sheath: A comparative histological and immunohistological study. Mod Pathol. 1995;8:155-159.

5. Dal Cin P, Sciot R, De Smet L, et al. Translocation 2;11 in a fibroma of tendon sheath. Histopathology. 1998;32:433-435.

6. Sciot R, Samson I, van den Berghe H, et al. Collagenous fibroma (desmoplastic fibroblastoma): Genetic link with fibroma of tendon sheath? Mod Pathol. 1999;12:565-568.

7. Park SY, Jin SP, Yeom B, et al. Multiple fibromas of tendon sheath: Unusual presentation. Ann Dermatol. 2011;23(Suppl 1):S45-S47.

8. Patterson J. Tumors and Tumor-Like Proliferations of Fibrous and Related Tissues. Weedon's Skin Pathology. 4th ed. St. Louis, MO: Elsevier; 2016

9. Ma D, Darling T, Moss J, et al. Histologic variants of periungual fibromas in tuberous sclerosis complex. J Am Acad Dermatol. 2011;64: 442-444.

10. Quist SR, Franke I, Sutter C, et al. Periungual fibroma (Koenen tumors) as isolated sign of tuberous sclerosis complex with tuberous sclerosis complex 1 germline mutation. $J$ Am Acad Dermatol. 2010;62:159-161.

11. Liebman JJ, Nigro LC, Matthews MS. Koenen tumors in tuberous sclerosis: A review and clinical considerations for treatment. Ann Plast Surg. 2014;73:721-722. 
12. Aldrich CS, Hong CH, Groves L, et al. Acral lesions in tuberous sclerosis complex: Insights into pathogenesis. J Am Acad Dermatol. 2010;63: 244-251.

13. Dereure O, Savoy D, Doz F, et al. Multiple acral fibromas in a patient with familial retinoblastoma: A cutaneous marker of tumour-suppressor gene germline mutation? Br J Dermatol. 2000;143:856-859.

14. Sleater J, Mullins D, Chun K, et al. Fibro-osseous pseudotumor of the digit: A comparison to myositis ossificans by light microscopy and immunohistochemical methods. J Cutan Pathol. 1996;23:373-377.

15. de Silva MV, Reid R. Myositis ossificans and fibroosseous pseudotumor of digits: A clinicopathological review of 64 cases with emphasis on diagnostic pitfalls. Int J Surg Pathol. 2003;11:187-195.

16. Dupree WB, Enzinger FM. Fibro-osseous pseudotumor of the digits. Cancer. 1986;58:2103-2109.

17. Moosavi CA, Al-Nahar LA, Murphey MD, et al. Fibroosseous [corrected] pseudotumor of the digit: A clinicopathologic study of 43 new cases. Ann Diagn Pathol. 2008;12:21-28.

18. Javdan M, Tahririan MA. Fibro-osseous pseudotumor of the digit. Adv Biomed Res. 2012;1:31.

19. Fletcher CDM, Bridge JA, Hogendoorn PCW, Mertens F, eds. WHO Classification of Tumours of Soft Tissue and Bone. Lyon, France: IARC; 2013.

20. Hollmann TJ, Bovée JV, Fletcher CD. Digital fibromyxoma (superficial acral fibromyxoma): A detailed characterization of 124 cases. Am J Surg Pathol. 2012;36:789-798.

21. Fetsch JF, Laskin WB, Miettinen M. Superficial acral fibromyxoma: A clinicopathologic and immunohistochemical analysis of 37 cases of a distinctive soft tissue tumor with a predilection for the fingers and toes. Hum Pathol. 2001;32:704-714.

22. Allen PW. The fibromatoses: A clinicopathologic classification based on 140 cases. Am J Surg Pathol. 1977;1:255-270.

23. Walker EA, Petscavage JM, Brian PL, et al. Imaging features of superficial and deep fibromatoses in the adult population. Sarcoma. 2012;2012: 215810.

24. Mahajan D, Billings SD, Goldblum JR. Acral soft tissue tumors: A review. Adv Anat Pathol. 2011;18:103-119.

25. Mehrotra AK, Sheikh S, Aaron AD, et al. Fibromatoses of the extremities: Clinicopathologic study of 36 cases. J Surg Oncol. 2000;74:291-296.

26. Ushijima M, Tsuneyoshi M, Enjoji M. Dupuytren type fibromatoses. A clinicopathologic study of 62 cases. Acta Pathol Jpn. 1984;34:991-1001.

27. Carlson JW, Fletcher CD. Immunohistochemistry for beta-catenin in the differential diagnosis of spindle cell lesions: Analysis of a series and review of the literature. Histopathology. 2007;51:509-514.

28. Laskin WB, Miettinen M, Fetsch JF. Infantile digital fibroma/fibromatosis: A clinicopathologic and immunohistochemical study of 69 tumors from 57 patients with long-term follow-up. Am J Surg Pathol. 2009;33: $1-13$.

29. Heymann WR. Infantile digital fibromatosis. $J$ Am Acad Dermatol. 2008;59:122-123.

30. Keasby LE. Juvenile aponeurotic fibroma (calcifying fibroma); a distinctive tumor arising in the palms and soles of young children. Cancer. 1953;6:338-346.

31. Fetsch JF, Miettinen M. Calcifying aponeurotic fibroma: A clinicopathologic study of 22 cases arising in uncommon sites. Hum Pathol. 1998;29: 1504-1510.

32. Kim OH, Kim YM. Calcifying aponeurotic fibroma: Case report with radiographic and MR features. Korean J Radiol. 2014;15:134-139.

33. Hocar O, Yacoubi H, Akhdari N, et al. Unusual presentation of a rare tumor of the dorsal surface of the foot. ISRN Dermatol. 2011;2011:704549.

34. Ushijima M, Hashimoto H, Tsuneyoshi M, et al. Giant cell tumor of the tendon sheath (nodular tenosynovitis). A study of 207 cases to compare the large joint group with the common digit group. Cancer. 1986;57: 875-884.

35. West RB, Rubin BP, Miller MA, et al. A landscape effect in tenosynovial giant-cell tumor from activation of CSF 1 expression by a translocation in a minority of tumor cells. Proc Natl Acad Sci U S A. 2006;103:690-695.
36. Won CY, Cho BK, Park HJ. Acral angioosteoma cutis on the great toe mimicking pyogenic granuloma. Ann Dermatol. 2015;27:480-481.

37. Song HJ, Hong WK, Han SH, et al. Acral angioosteoma cutis. Am J Dermatopathol. 2010;32:477-478.

38. Lee EJ, Lee JH, Shin MK, et al. Acral angioosteoma cutis. Ann Dermatol. 2011;23(Suppl 1):S105-S107.

39. Hazani R, Houle JM, Kasdan ML, et al. Glomus tumors of the hand. Eplasty. 2008;8:e48.

40. Bhaskaranand K, Navadgi BC. Glomus tumour of the hand. $J$ Hand Surg Br. 2002;27:229-231.

41. Giele H. Hildreth's test is a reliable clinical sign for the diagnosis of glomus tumours. $J$ Hand Surg Br. 2002;27:157-158.

42. Maehara LS, Ohe EM, Enokihara MY, et al. Diagnosis of glomus tumor by nail bed and matrix dermoscopy. An Bras Dermatol. 2010;85:236-238.

43. Haenssle HA, Blum A, Hofmann-Wellenhof R, et al. When all you have is a dermatoscope- start looking at the nails. Dermatol Pract Concept. 2014;4:11-20.

44. Urmacher C. Normal skin. In: Mills SE, ed. Histology for Pathologists. 3rd ed. Philadelphia: Lippincott Williams \& Wilkins; 2007.

45. Gombos Z, Zhang PJ. Glomus tumor. Arch Pathol Lab Med. 2008;132: 1448-1452.

46. Folpe AL, Fanburg-Smith JC, Miettinen M, et al. Atypical and malignant glomus tumors: Analysis of 52 cases, with a proposal for the reclassification of glomus tumors. Am J Surg Pathol. 2001;25:1-12.

47. Kamarashev J, French LE, Dummer R, et al. Symplastic glomus tumor-a rare but distinct benign histological variant with analogy to other 'ancient' benign skin neoplasms. J Cutan Pathol. 2009;36:1099-1102.

48. Chong Y, Eom M, Min HJ, et al. Symplastic glomus tumor: A case report. Am J Dermatopathol. 2009;31:71-73.

49. Armijo M. Mucoid cysts of the fingers. Differential diagnosis, ultrastructure, and surgical treatment. J Dermatol Surg Oncol. 1981;7:317-322.

50. Butler DF, Davis G, Greene JF. Multiple mucinous (myxoid) cysts of a single finger. $J$ Am Acad Dermatol. 2005;53:914-916.

51. Salerni G, González R, Alonso C. Dermatoscopic pattern of digital mucous cyst: Report of three cases. Dermatol Pract Concept. 2014;4:65-67.

52. Salerni G, Alonso C. Images in clinical medicine. Digital mucous cyst. $N$ Engl J Med. 2012;366:1335.

53. Fetsch JF, Miettinen M. Sclerosing perineurioma: A clinicopathologic study of 19 cases of a distinctive soft tissue lesion with a predilection for the fingers and palms of young adults. Am J Surg Pathol. 1997;21: $1433-1442$

54. Vargas TJ, Sousa MA, Sampaio AL, et al. Sclerosing perineurioma: Case report and literature review. An Bras Dermatol. 2009;84:643-649.

55. Grimer R, Judson I, Peake D, et al. Guidelines for the management of soft tissue sarcomas. Sarcoma. 2010;2010:506182.

56. Spillane AJ, Thomas JM, Fisher C. Epithelioid sarcoma: The clinicopathological complexities of this rare soft tissue sarcoma. Ann Surg Oncol. 2000; 7:218-225.

57. Hocar O, Le Cesne A, Berissi S, et al. Clear cell sarcoma (malignant melanoma) of soft parts: A clinicopathologic study of 52 cases. Dermatol Res Pract. 2012;2012:984096.

58. Fisher C. Epithelioid sarcoma of Enzinger. Adv Anat Pathol. 2006;13: 114-121.

59. Wolf PS, Flum DR, Tanas MR, et al. Epithelioid sarcoma: The University of Washington experience. Am J Surg. 2008;196:407-412.

60. Guzzetta AA, Montgomery EA, Lyu H, et al. Epithelioid sarcoma: One institution's experience with a rare sarcoma. J Surg Res. 2012;177: 116-122.

61. Ieremia E, Thway K. Myxoinflammatory fibroblastic sarcoma: Morphologic and genetic updates. Arch Pathol Lab Med. 2014;138: 1406-1411.

62. Montgomery EA, Devaney KO, Giordano TJ, et al. Inflammatory myxohyaline tumor of distal extremities with virocyte or Reed-Sternberg-like cells: A distinctive lesion with features simulating inflammatory conditions, Hodgkin's disease, and various sarcomas. Mod Pathol. 1998;11: 384-391. 
63. Elco CP, Mariño-Enríquez A, Abraham JA, et al. Hybrid myxoinflammatory fibroblastic sarcoma/hemosiderotic fibrolipomatous tumor: Report of a case providing further evidence for a pathogenetic link. Am J Surg Pathol. 2010;34:1723-1727.

64. Laskowski J. Aponeurotic sarcoma. Pol Med J. 1971;10:12-17.

65. Enzinger FM. Epitheloid sarcoma. A sarcoma simulating a granuloma or a carcinoma. Cancer. 1970;26:1029-1041.

66. Guillou L, Wadden C, Coindre JM, et al. "Proximal-type" epithelioid sarcoma, a distinctive aggressive neoplasm showing rhabdoid features. Clinicopathologic, immunohistochemical, and ultrastructural study of a series. Am J Surg Pathol. 1997;21:130-146.

67. Sakharpe A, Lahat G, Gulamhusein T, et al. Epithelioid sarcoma and unclassified sarcoma with epithelioid features: clinicopathological variables, molecular markers, and a new experimental model. Oncologist. 2011;16:512-522.

68. Chbani L, Guillou L, Terrier P, et al. Epithelioid sarcoma: A clinicopathologic and immunohistochemical analysis of 106 cases from the French sarcoma group. Am J Clin Pathol. 2009;131:222-227.
69. Hornick JL, Dal Cin P, Fletcher CD. Loss of INI1 expression is characteristic of both conventional and proximal-type epithelioid sarcoma. Am J Surg Pathol. 2009;33:542-550.

70. Agaimy A. The expanding family of SMARCB1(INI1)-deficient neoplasia: Implications of phenotypic, biological, and molecular heterogeneity. Adv Anat Pathol. 2014;21:394-410.

71. Enzinger FM. Clear-cell sarcoma of tendons and apoeneuroses. An analysis of 21 cases. Cancer. 1965;18:1163-1174.

72. Hisaoka M, Ishida T, Kuo TT, et al. Clear cell sarcoma of soft tissue: A clinicopathologic, immunohistochemical, and molecular analysis of 33 cases. Am J Surg Pathol. 2008;32:452-460.

73. Karamchandani JR, Nielsen TO, van de Rijn M, et al. Sox10 and S100 in the diagnosis of soft-tissue neoplasms. Appl Immunohistochem Mol Morphol. 2012;20:445-450.

74. Song JS, Choi J, Kim JH, et al. Diagnostic utility of EWS break-apart fluorescence in situ hybridization in distinguishing between non-cutaneous melanoma and clear cell sarcoma. Pathol Int. 2010;60:608-613. 